\title{
ANALYSIS OF TECHNOLOGY ACCEPTANCE OF ENTERPRISE RESOURCE PLANNING (ERP) SYSTEM IN THE REGIONAL OFFICE OF PT. XYZ THROUGHOUT INDONESIA
}

\author{
Baiq Findiarin Billyan ${ }^{1}$ | Mohammad Isa Irawan*2
}

\footnotetext{
${ }^{1}$ Dept. of Management Technology, Institut Teknologi Sepuluh Nopember, Surabaya, Indonesia

${ }^{2}$ Dept. of Mathematics, Institut Teknologi Sepuluh Nopember, Surabaya, Indonesia
}

\section{Correspondence}

*Mohammad Isa Irawan, Dept of Mathematics, Institut Teknologi Sepuluh Nopember, Surabaya, Indonesia. Email: mii@its.ac.id

\section{Present Address}

Gedung Magister Manajemen Teknologi ITS, Jl. Cokroaminoto No. 12A, Surabaya 60264, Indonesia

\begin{abstract}
The companies that started to renew their system using ERP-based systems, since 2000 the percentage of success reached $75 \%$, and $25 \%$ is a failure. There are several issues such as the quality of human resources, not user-friendly system, incorrect format for data recording, system errors, unstable connections, the long-time process in the system, etc. Related to the issue, the ERP SAP technology provider provides local support to help end-users use the system for daily work. In this study, to analyze the factors of acceptance technology of ERP system, we use the UTAUT2 method, and for analyzing those hypotheses, we use the PLS-SEM method.
\end{abstract}

\section{KEYWORDS:}

ERP, PLS-SEM, SAP, Technology Acceptance, UTAUT2

\section{1 | INTRODUCTION}

Innovations in rapidly developing technology have a significant impact nowadays, making the companies also update their systems. This phenomenon makes the companies update and move their system to ERP-based systems. Previous research ${ }^{10}$ has implemented ERP systems since 2000, but the successful acceptance percentage is still $75 \%$ and $25 \%$ failure. Several issues include quality of human resources, systems that are not user-friendly, errors in the recording process, frequent errors that happened in the systems, unstable connection, the connection to the system must be stable, the long system process, and so on.

In 2019, finance company PT. XYZ applied an ERP system known as SAP in its regional offices throughout Indonesia. In its implementation, there is a problem that the target user acceptance does not run according to the scheduled time, which impacts project delays. This paper aims to analyze the acceptance factors at all regional offices in Indonesia for companies that implement SAP FICO and SAP MM in their systems. 
The company that provides and markets the SAP system provides services and develops the system based on the client company's request. It also provides technical support for implementing the data recording process at selected divisions that use this system for their daily work. The support involves local support (LS) or implementors. The local support is expected to help overcome some problems and know which part of the system is said about not being user-friendly so that it is possible to help users in data processing and recording. This need motivates this study. This study analyzed the fundamental factors that affect users' acceptance of the SAP ERP system technology at the company's regional offices. By looking at the performance of regional office users who are assisted by the local support, does the assistance by local support influence the implementation of the system in the company regional offices.

The model used to analyze the factors in this research is the Unified Theory of Acceptance and Use of Technology (UTAUT2). UTAUT $^{[2]}$ is a model with the latest technology acceptance concept, the best method used by many technology industries chosen by experts. This model is also known to collaborate with several older models such as the Innovation Diffusion Theory (IDT), Motivational Model (MM), Model of PC Utilization (MPCU), Social Cognitive Theory (SCT) Technology Acceptance Model (TAM), Theory of Planned Behavior (TPB), The Theory of Reasoned Action (TRA), and Combined TAM and TPB (c-TAM-TPB).

In this research, we added construct-variable, i.e., trust and learning value. Hypotheses testing was conducted using Partial Least Square Structural Equation Modeling (PLS-SEM) method. This quantitative research conducted a survey that involved 87 respondents on the SAP FICO and MM modules from management to staff levels. The respondents are users who use ERP technology with SAP applications in all regional offices of PT. XYZ in Indonesia and accompanied by local support. This study's expected results are to obtain the most influential factors in accepting ERP technology and recommendations for future use by ERP technology providers as references in further development and projects. Suppose the assistance of local support does affect the system implementation. In that case, this should help regional office users smoothen the implementation process related to recording if there is a possibility that recording will not be carried out according to the rules

\section{2 | LITERATURE STUDY}

Acceptance of technology can be defined as a user willing to work with technology designed as a support to carry out their tasks ${ }^{3]}$. From previous research, many studies have been conducted to understand the acceptance of technology in a business context because of the close relationship formed between the use of appropriate technology and its profit limits. In many of these studies, researchers have attempted to identify and understand the type of user acceptance that influences the design and implementation process to avoid or minimize resistance or resistance when users interact with technology.

Many experts emphasize the importance of proper education and training for both employees and managers. Many people will naturally resist changing the way they do their jobs. Many analysts noted that support from higher-up management to achieve successful adoption and implementation is as important as changes in company size. ERP is an integrated system for each division in a company to help its main and important administrative processes run in a logic database so that all divisions can store and retrieve their information in real-time ${ }^{44}$. The results of data integration in the system will produce the final report for the company. Companies and organizations can achieve the best competitive advantage by carefully managing training and education, as long as system activities are well integrated ${ }^{[5]}$.

There are several causes of ERP implementation failure, which are described in the following conditions 11 :

- Poor planning. Planning should include several business-related issues and user availability for system configuration decisions.

- Poor project management. There are only a few companies that make ERP without involving a consultant.

- Lack of software evaluation. Organizations or companies do not understand what and how ERP system works and other reasons.

In 1972, System Analysis and Program Development (SAP Company) was the first company to develop applications for ERP systems used to complete $50 \%$ of business transactions globally. The vision of SAP is the development of standard software applications in real-time business processes. It was first created for accounting applications. Then SAP forms the basis for 
continuing application development ${ }^{[2]}$. SAP is a software that provides information from a business transaction resulting from the merger of departments as a facilitator for decision making ${ }^{[3]}$.

UTAUT $^{[4]}$ is a model with the concept of acceptance of the latest technology, which is known to be the best method by experts in many technology-related industries. This model is also known to collaborate with several older models such as Innovation Diffusion Theory (IDT), Motivational Model (MM), Model of PC Utilization (MPCU), Social Cognitive Theory (SCT), Technology Acceptance Model (TAM), Theory of Planned Behavior (TPB), The Theory of Reasoned Action (TRA), and Combined TAM and TPB (c-TAM-TPB).

There are four main constructs that directly affect user's acceptance and usage habits, i.e., performance expectancy, social influence, facilitating conditions, and effort expectancy ${ }^{[4}$. In contrast to the theories, the are three main constructs that do not directly affect usage habits, i.e., behavior towards technology use, self-efficacy, and anxiety. The label used as the construct describes the essence of the construct and is intended not to depend on a particular theoretical perspective. In this case, certain constructs are used as determinants of the main moderator, such as gender, age, voluntariness, and experiences. UTAUT has several advantages compared to other technology acceptance methods in terms of the variables covered. The UTAUT method combines the variables in the previous method in a major concept, impacting user perceptions and their reactions to technology that UTAUT method is understood to be better than the previous method. Then, many countries can use the UTAUT method, and it is quite good because it can be translated into various languages [6].

According to Venkatesh et al. [5], where UTAUT2 is a continuation of the UTAUT method, it has seven constructs that affect behavioral intention and use behavior. It consists of four main constructs. Those are performance expectancy, effort expectancy, social influence, facilitating conditions. Then in this advanced method, we added three constructs, habit, hedonic motivation, and price value. However, the voluntariness moderator was removed. The construct is mediated using the mediators of age, gender, and experience. UTAUT2 has advantages in the range of existing variables because the method combines the existing variables in the main concept. This method also has the objective of describing a person's interest in using an information technology system and user behavior.

SEM is a class of multivariate techniques that combines factor analysis and regression aspects, enabling the researcher to simultaneously examine the relationship between measured and latent variables and between latent variables. SEM is a statistical model that could analyze a pattern of relationships from a hypothetical relationship between variables on the indicator and its latent constructs, direct or indirect measurement errors, and latent constructs with each other 7 .

In the SEM method, the researcher can carry out several activities at once, such as testing the relationship model between latent variables (equivalent to path analysis), obtaining a model that is useful for prediction (equivalent to regression analysis and structural models), and testing the relationship model between latent variables (equivalent with path analysis).

The characteristic of SEM as an analytical technique is that it can confirm rather than explain. A researcher prefers SEM in determining a particular model that is valid or not, rather than using SEM to find whether the model is suitable or not, even though SEM often includes the elements used to describe. Whereas, it is necessary to make a type of hypothesis consisting of structural types and measurements in the form of path diagrams which are initially based on theoretical justification before using SEM.

There are two types of approaches in the SEM method, the variance approach (VB-SEM) with the Partial Least Squares-SEM (PLS-SEM) technique, and covariance-based SEM or also known as Covariance Based-SEM (CB-SEM). PLS is a powerful analytical method because it can be used in any data scale such as ordinal, interval, nominal, and ratio, without using many assumptions that must be met. The difference between PLS-SEM and CB-SEM is that CB-SEM focuses more on making methods to explain the covariances of all construct indicators. PLS-SEM has a predictive objective and is more suitable because it assumes all variance measures are useful variances to explain.

This tool was developed in 2005 by Professor Cristian M. Ringle, Sven Wended, and Alexander Will. SmartPLS is software that is used as a tool to perform PLS-SEM analysis 7 . The tool has a user-friendly GUI that users can understand enough in estimating the PLS path model. For problem-solving aspect can be discussed through the forums provided by this website tool.

There are several advantages of the tools, which are the reason researchers used the SmartPLS tool in this study, described as follows. 


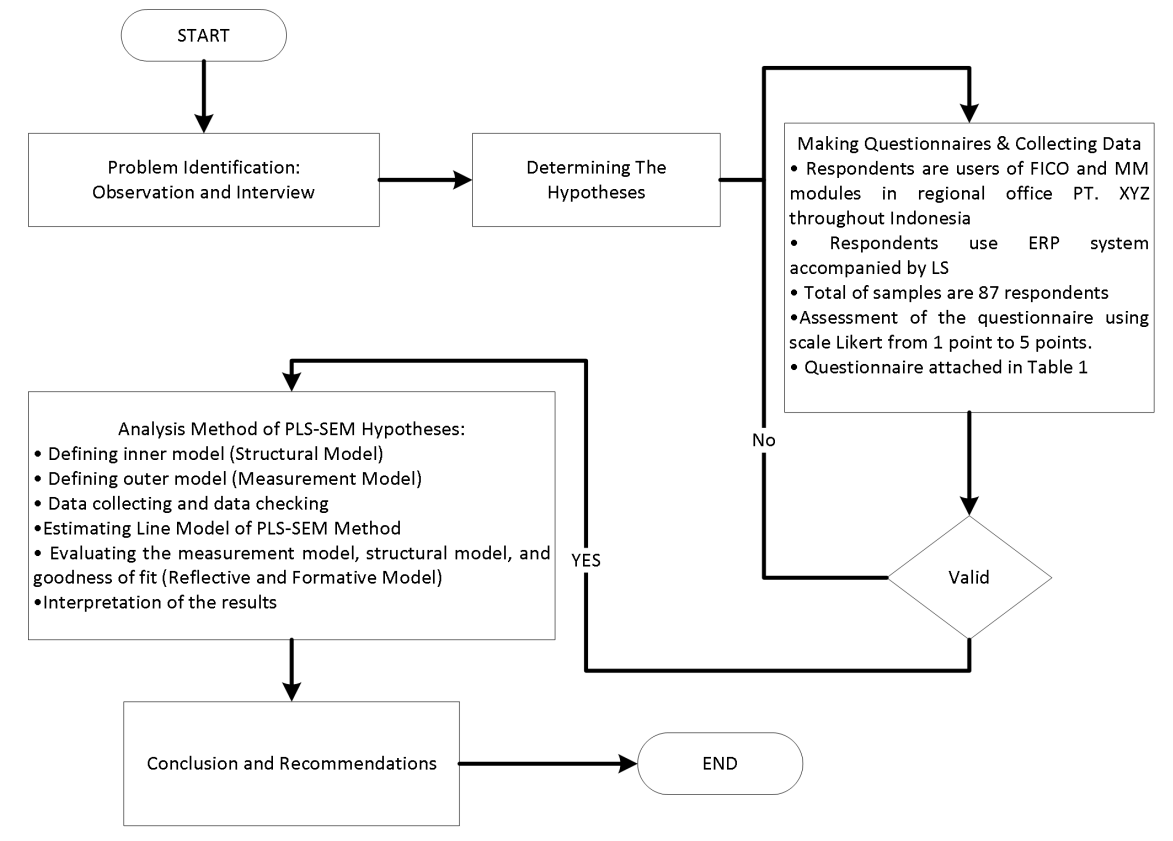

FIGURE 1 Flowchart of Research Methodology.

- When the data distribution is very skewed, and the independence between the observational data in the research cannot be guaranteed, the SmartPLS tool can be used.

- PLS method has an algorithm that is not limited only to the relationship between indicators and latent constructs that have reflective properties but also can be used in relationships that have formative properties. Data that have complex models and has a very small number of samples can also use this tool.

\section{3 | MATERIAL AND METHOD}

\section{1 | Research Methodology}

The procedure and method implemented in this research are presented in Figure 1

In this stage, we identify problems through observation and interviews. The observation is conducted by interacting and looking at the application's user management, how the user uses the application, etc. For the interview, we asked several personnel such as the marketing, HRD, admin, consultant, local support, and system users at one of the regional offices at PT. XYZ. The questions are regarding the system, its utilization, and questions related to local support. After that, we determine the research objectives to determine what factors influence the acceptance of ERP technology using the UTAUT2 method. Then we analyze these factors using the PLS-SEM method.

After formulating problems and research objectives, the next step is examination. In this stage, examine some literature related to this research to know and understand the limits. The literature study in this research is from several books, previous research, papers, and journals related to the research conducted in this study.

\section{2 | Research Design}

To know factors associated with the acceptance of ERP technology in this study, we use a conceptual model based on several previous studies and test new findings. The research is conducted as quantitative research using an approach through surveys.

Based on previous research [5], UTAUT2 has seven constructs that affect behavioral intention and user behavior. It consists of four main constructs, i.e., performance expectancy, effort expectancy, social influence, facilitating conditions, and the other three additional constructs are habit, hedonic motivation, and price value. UTAUT2 is implemented in this research because 


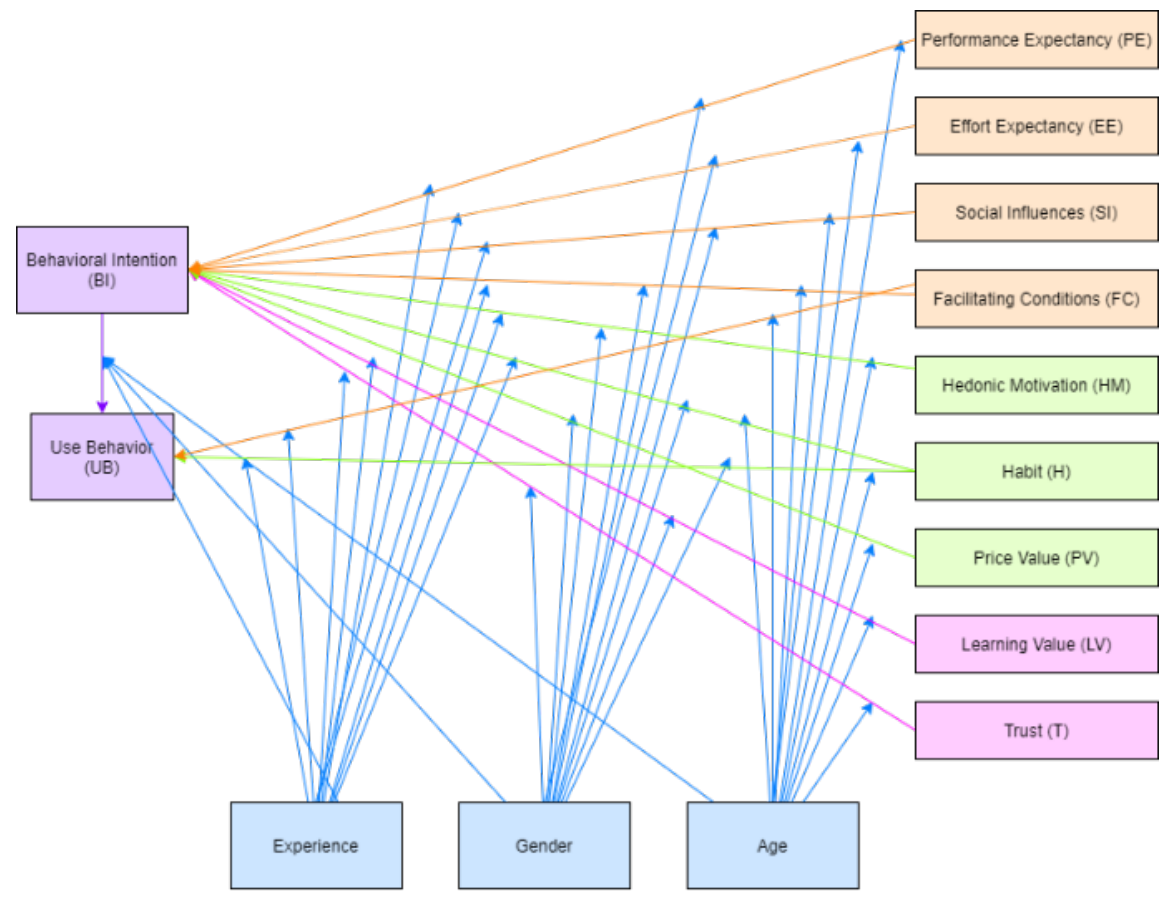

FIGURE 2 Illustration of UTAUT2 Development.

this method is a new technology acceptance concept, which experts believe to be one of the best methods. This method is also widely used by the technology-related industry. In this study, we added two construct variables, namely trust and learning value. Trust variable $(\mathrm{T})$ is added because, according to El-Masri and Tarhini ${ }^{[8]}$, the trust variable is a variable that influences the acceptance of technology. In previous research, learning value is added as a variable because it also significantly influences the research. An illustration of the development of the UTAUT2 method for this study is presented in Figure 2

The explanations related to the constructed model of UTAUT2 in Figure 2 are described as follows.

1. Performance Expectancy (PE): to determine how a person believes that using this technology can help him improve his work performance.

2. Effort Expectancy (EE): to know the level of ease related to using the technology.

3. Social Influence (SI): to know the level of environmental influence in using the technology.

4. Facilitating Conditions (FC): to find out the organization's infrastructure and technical support that helps users use the technology.

5. Hedonic Motivation (HM): to find out does the user obtains some pleasure, enjoyment, or sense of happiness when using the technology.

6. Price Value (PV): to know the comparison level between costs to buy the technology and benefits obtained when using the technology.

7. Habit $(\mathrm{H})$ : to find out to what extent individuals tend to do a behavior automatically because they knew it beforehand.

8. Learning Value (LV): to know from the utilization of technology products can hold value if they provide some benefits.

9. Trust (T): to know the belief in the use of technology and cause interdependence.

10. Behavioral Intention (BI): to find out behavioral intention, defined as a person who has a perceived probability or subjective probability that he will be involved in a particular behavior. 
11. Use Behavior (UB): to find out the actual frequency of users of technology usage.

\section{3 | Research Hypotheses}

In this section, we present the hypotheses related to UTAUT2 that will be tested in this research.

- H1: Regarding age, gender, and experience variables, does PE has a positive effect on BI.

- H2: Regarding age, gender, and experience variables, does EE has a positive effect on BI.

- H3: Regarding age, gender, and experience variables, does SI has a positive effect on BI.

- H4: Regarding age, gender, and experience variables, does FC has a positive effect on BI.

- H5: Regarding age, gender, and experience variables, does HM has a positive effect on BI.

- H6: Regarding age and gender, experience, does PV has a positive effect on BI.

- H7: Regarding age, gender, and experience variables, does Habit $(\mathrm{H})$ have a positive effect on BI.

- H8: Regarding age, gender, and experience variables, does FC has a positive effect on UB.

- H9: Regarding age, gender, and experience variables, does Habit $(\mathrm{H})$ have a positive effect on UB.

- H10: Regarding age, gender, and experience, does BI has a positive effect on UB.

- H11: Regarding age, gender, and experience variables, does Trust (T) has a positive effect on BI.

- H12: Regarding age, gender, and experience variables, does LV has a positive effect on BI.

\section{4 | Questionnaire and Collecting Data}

This research uses a questionnaire as a medium for data collection. The questions given on the questionnaire are also structured questions with alternative answers provided online through several communication media using the Google Forms website. The questionnaire is filled out independently by respondents who also called a self-administered survey. The questionnaire assessment uses the Likert scale with a range of 1 to 5. The data were obtained online from the SAP ERP system users in all Indonesia regional offices and local support. Users of the SAP ERP system are users of the SAP FICO and SAP MM modules. The data will be used to determine what factors affect the acceptance of ERP technology.

\subsubsection{Questionnaire Indicators and Variables}

The questions in the questionnaire were based on the information, which consists of variables that would be studied in this research. There are nine independent variables, three moderators, and two dependent variables. The independent variables consisted of price value, habit, performance expectancy, effort expectancy, hedonic motivation, social influence, facilitating condition, trust, and learning value. The moderator variables such as gender, age, and experience. The dependent variables such as use behavior and behavioral intention.

Questions related to variable behavior intention and independent variables are measured using the Likert scale. On the Likert scale, one means Strongly Disagree; two means Disagree; tree for the category Neutral; four means Agree; five means Strongly Agree.

The assessment for questions regarding the use behavior variable is described as follows. Point- 1 is for the intensity of use at least once a year. Point- 2 is for the intensity of use at least once per semester. Point- 3 is for the intensity of use at least once per month. Point- 4 is for the intensity of use at least once per week. Finally, points-5 for the intensity of use as much as each day 
TABLE 1 Details of variables, indicators, questions, and references.

\begin{tabular}{|c|c|c|c|}
\hline Variable & Indicator & Question Item & Reference \\
\hline \multirow{4}{*}{$\begin{array}{l}\text { Performance } \\
\text { Expectancy } \\
\text { (X.1) }\end{array}$} & Usability (X.1.1) & Usefulness in daily life. & \multirow[t]{4}{*}{$\begin{array}{l}\text { Venkatesh } \\
\text { et al. }[5]\end{array}$} \\
\hline & $\begin{array}{l}\text { Opportunities improvement } \\
\text { (X.1.2) }\end{array}$ & Improvement in future opportunities. & \\
\hline & Structured solution (X.1.3) & Helps complete tasks in more detail & \\
\hline & $\begin{array}{l}\text { Productivity improvement } \\
\text { (X.1.4) }\end{array}$ & ERP system can improve the productivity & \\
\hline \multirow{4}{*}{$\begin{array}{l}\text { Effort } \\
\text { Expectancy } \\
(\mathrm{X} .2)\end{array}$} & Easy to understand (X.2.1) & $\begin{array}{l}\text { ERP system is easy to understand with the assistance of local } \\
\text { support. }\end{array}$ & \multirow[t]{4}{*}{$\begin{array}{l}\text { Venkatesh } \\
\text { et al. }[5]\end{array}$} \\
\hline & Easy to use (X.2.2) & ERP system is easy to use with the assistance of local support. & \\
\hline & $\begin{array}{l}\text { Easy to learn the new feature } \\
\text { (X.2.3) }\end{array}$ & $\begin{array}{l}\text { A new feature in the ERP system is easy to learn with the assistance } \\
\text { of local support. }\end{array}$ & \\
\hline & $\begin{array}{l}\text { Easy to become proficient } \\
\text { (X.2.4) }\end{array}$ & $\begin{array}{l}\text { The assistance of local supports makes it easy to become proficient } \\
\text { in using the ERP system. }\end{array}$ & \\
\hline \multirow{3}{*}{$\begin{array}{l}\text { Social } \\
\text { Influence (X.3) }\end{array}$} & Nearby users (X.3.1) & Acquaintances who use ERP system & \multirow{3}{*}{$\begin{array}{l}\text { Venkatesh } \\
\text { et al. }[5]\end{array}$} \\
\hline & $\begin{array}{l}\text { Perceptions of surrounding } \\
\text { people (X.3.2) }\end{array}$ & People around who think should use ERP systems. & \\
\hline & $\begin{array}{l}\text { Influences of surrounding } \\
\text { people (X.3.3) }\end{array}$ & The surrounding people that influence to use ERP system. & \\
\hline \multirow{3}{*}{$\begin{array}{l}\text { Facilitating } \\
\text { Conditions } \\
(\mathrm{X} .4)\end{array}$} & $\begin{array}{l}\text { Owning the knowledge } \\
\text { (X.4.1) }\end{array}$ & $\begin{array}{l}\text { The assistance of local support gives the required knowledge to use } \\
\text { the ERP system. }\end{array}$ & \multirow[t]{3}{*}{$\begin{array}{l}\text { Venkatesh } \\
\text { et al. }[5]\end{array}$} \\
\hline & Compatibility (X.4.2) & $\begin{array}{l}\text { ERP system is compatible with other technology that is currently in } \\
\text { use. }\end{array}$ & \\
\hline & Help (X.4.3) & $\begin{array}{l}\text { Get help or assistance from other people or local support when } \\
\text { having trouble using the ERP system. }\end{array}$ & \\
\hline \multirow{3}{*}{$\begin{array}{l}\text { Hedonic } \\
\text { Motivation } \\
\text { (X.5) }\end{array}$} & Pleasure in use (X.5.1) & It makes the user happy when the user completes the transaction. & \multirow[t]{3}{*}{$\begin{array}{l}\text { Venkatesh } \\
\text { et al. [5] }\end{array}$} \\
\hline & Necessity (X.5.2) & Using an ERP system all the time is a necessity. & \\
\hline & Willingness to use (X.5.3) & Willingness to be a part that can use an ERP system. & \\
\hline \multirow{3}{*}{$\begin{array}{l}\text { Price Value } \\
\text { (X.6) }\end{array}$} & Cost (X.6.1) & ERP system is affordable for companies. & \multirow[t]{3}{*}{$\begin{array}{l}\text { Venkatesh } \\
\text { et al. }[5]\end{array}$} \\
\hline & $\begin{array}{l}\text { Benefits compared to costs } \\
\text { (X.6.2) }\end{array}$ & $\begin{array}{l}\text { ERP system provides more benefits than the costs incurred by the } \\
\text { company. }\end{array}$ & \\
\hline & $\begin{array}{l}\text { Value compared to costs } \\
\text { (X.6.3) }\end{array}$ & $\begin{array}{l}\text { ERP system provides more value than the costs incurred by the } \\
\text { company (good value for the money). }\end{array}$ & \\
\hline \multirow[t]{2}{*}{ Habit (X.7) } & Habit (X.7.1) & Using an ERP system has become a habit. & \multirow[t]{2}{*}{$\begin{array}{l}\text { Venkatesh } \\
\text { et al. }{ }^{-5]}\end{array}$} \\
\hline & Necessity (X.7.2) & The necessity to use an ERP system. & \\
\hline \multirow{4}{*}{$\begin{array}{l}\text { Learning Value } \\
\text { (X.8) }\end{array}$} & $\begin{array}{l}\text { Benefit compares to efforts } \\
\text { (X.8.1) }\end{array}$ & $\begin{array}{l}\text { ERP system is worth more than the effort put in (good value for the } \\
\text { effort). }\end{array}$ & \multirow[t]{4}{*}{$\begin{array}{l}\text { Ain } \\
\text { et al. }[9]\end{array}$} \\
\hline & Easy to interact with (X.8.2) & ERP system makes it possible to share knowledge with others easily. & \\
\hline & Opportunity to learn (X.8.3) & ERP system allows deciding on the pace of learning. & \\
\hline & Opportunity (X.8.4) & ERP system gives opportunities to increase knowledge. & \\
\hline \multirow[t]{3}{*}{ Trust (X.9) } & User's importance (X.9.1) & $\begin{array}{l}\text { Trust in ERP system service providers who prioritize the interests } \\
\text { of users. }\end{array}$ & \multirow[t]{3}{*}{$\begin{array}{l}\text { Gefen } \\
\text { et al. } 10] \\
\text { Chandra } \\
\text { et al. }\end{array}$} \\
\hline & Reliability (X.9.2) & ERP system service providers can be trusted & \\
\hline & $\begin{array}{l}\text { Performance (X.9.3) } \\
\text { Security (X.9.4) }\end{array}$ & $\begin{array}{l}\text { Technology implemented in ERP system has a good performance. } \\
\text { The technology has a secure system }\end{array}$ & \\
\hline \multirow{3}{*}{$\begin{array}{l}\text { Behavioral } \\
\text { Intention (Y.1) }\end{array}$} & Intention (Y.1.1) & The intention to continue using the ERP system in the future. & \multirow{3}{*}{$\begin{array}{l}\text { Venkatesh } \\
\text { et al. }[5]\end{array}$} \\
\hline & Behavior (Y.1.2) & Use ERP System in daily life & \\
\hline & Interest to use (Y.1.3) & Interest in continuing to use the ERP system as often as possible. & \\
\hline \multirow{2}{*}{$\begin{array}{l}\text { Use Behavior } \\
\text { (Y.2) }\end{array}$} & Intensity (Y.2.1) & The intensity in using the ERP system & \multirow[t]{2}{*}{$\begin{array}{l}\text { Venkatesh } \\
\text { et al. }[5]\end{array}$} \\
\hline & Experience (Y.2.2) & Duration of using the ERP system & \\
\hline
\end{tabular}

\subsection{2 | Questionnaire Structure}

The questionnaire structure consisted of two parts, i.e. the respondents' demographic data questions and the main questions. The questions regarding respondents' demographic data include name, domicile, gender, age, marital status, and educational background. The main questions about the research. Table 1 represents questions that were used to measure the attributes for this research. 


\section{5 | Validity and Reliability Testing}

In this procedure, we conduct a test on the questionnaire before distributing it to the respondents. The purpose is to check does the questionnaire meets the requirements for good measurement media according to the standard of research methodology. Besides that, this step also aims to find out the respondents' understanding of the questions in the questionnaire so that the respondents will give appropriate answers. If there are deficiencies, then improvements would be made to the questionnaire. The results would be revised again until a questionnaire is formed with questions whose contents are understandable and do not contain ambiguity to the respondent. The revised questionnaire will be distributed to all respondents as the sample data used in this study.

The validity test aims to find out to what extent the instruments used in this study can be used to measure what should be measured by asking for opinions and judgments from other people who are more competent regarding the problem in this research. A reliability test aims to determine the extent to which a measurement result can be consistent if an instrument is used repeatedly. If there is an error in the measurement, it will impact different results on the measurement of the same object.

\section{6 | Data Processing}

The data processing process in this study uses analysis and assessment using the SEM method. The steps are explained as follows.

\subsection{1 | Data Analysis using PLS-SEM Method}

PLS-SEM method process the data obtained from the completed questionnaire. Here we use outer model and inner model testing. Inner model testing using $R^{2}$ calculation aims to determine the value of BI and UB and their effect on the acceptance of ERP technology. The next step is to analyze the influencing variables using t-value analysis and bootstrapping on the PLS-SEM method. Based on Ketchen ${ }^{[7]}$, there are several steps in the PLS-SEM analysis. It consists of six steps.

The first step is defining outer model. The outer model represents the relationship between indicator variables and constructs variables that measure it in determining the nature of the formative or reflective types. For constructs, it has a single item and multi-item measurement types. The formula for the outer model equation is as follows.

$$
\begin{aligned}
& x=\prod_{x} \xi+\epsilon_{x} \\
& y=\prod_{y} \eta+\epsilon_{x}
\end{aligned}
$$

Where $x$ and $y$ are the matrix of variable manifest independent and dependent; $\xi$ and $\eta$ are the matrix of variable latent independent and dependent; $\Pi$ is the matrix coefficient (matrix loading); and $\varepsilon$ is residue matrix outer model.

The second step is defining inner model. Defining the inner model aims to model the relationship between latent variables. It is necessary to pay attention to describing a relationship and hypotheses on the theory being tested. The formula for the inner model equation used is explained as follows.

$$
\eta=\beta \eta+r \xi+\zeta
$$

Where $\eta$ is the matrix construct latent endogen; $\beta$ is the coefficient matrix variable endogen; $r$ is the coefficient matrix variable exogen; $\xi$ is the matrix construct latent endogen; and the $\zeta$ is the residual of inner matrix model.

In addition, to calculate the R-square value, we can evaluate the Q-square predictive of its relevance by the model and its parameter estimation. If the Q-square value is $>0$, it means that the model has a relevant prediction. On the other hand, if the Q-square value is $\leq 0$, the model has less relevant predictions. The Q-square formula can be described as follows.

$$
Q^{2}=1-\left(1-R_{1^{2}}\right)\left(1-R_{2^{2}}\right) \ldots\left(1-R_{p^{2}}\right)
$$


Where $R_{1^{2}}, R_{2^{2}}, \ldots, R_{p^{2}}$ is R-Square of endogen variable $Q^{2}$, which has a value in the range $0<Q^{2}<1$, means that the closer to the value 1 , the better. The magnitude of $Q^{2}$ is equivalent to the total coefficient of determination in the path analysis.

The third step is collecting and checking data. If the collected data contains answers from respondents that are not filled in, it is necessary to indicate a missing value. If the missing value in each indicator is relatively small, for example, less than 5\%, it is recommended to replace the mean value instead of casewise deletion. Outlier diagnostics is used for the inspection.

The fourth step is estimating path model using PLS-SEM method. A path diagram is needed to describe the relationship between constructs and indicators. The construct can make it easier to see the model as a whole. In this path model estimation, the PLS method makes parameter estimates and other model path coefficients to maximize the type (variance) described by the dependent variable. This indicator variable is used to input raw data in estimating the value of the construct as a form of completion of the PLS-SEM method.

The fifth step is evaluating the measurement model, structural, and goodness of Fit (GOF). This process aims to evaluate the model as a form of validity and reliability of its indicators. The reflective measurement model evaluates with average variance extracted to assess convergent validity and composite reliability to assess internal consistency and individual indicator reliability. Also, to assess discriminant validity using cross-loading calculations and Fornell-Lacker criterion.

For the structural model, the objective is to determine the relationship between latent variables and the path coefficient, indicating whether there is a significant relationship in this research method or not. The step taken is to look at the R-Square $\left(R^{2}\right)$ value for each prediction from the structural model. This value will explain the effect of a certain exogenous (latent variable) on endogenous (latent variable) or how much influence it has.

There are several types of Goodness of Fit, i.e., outer reflective, formative, and GOF and inner models. The reflective model was evaluated based on the convergent seen from the loading factor value. The value can be considered sufficient between 0.5 to 0.6 and preferably greater than 0.7 . while for the number of latent variables between 3 to 7 . Furthermore, discriminant validity is seen based on the existing AVE value of $>0.5$, while composite reliability is $>0.6$.

The equation of the AVE calculation is stated by Equation 1

$$
A V E=\frac{\sum \lambda_{i^{2}}}{\sum \lambda_{i^{2}} \sum \lambda_{i} \operatorname{var}\left(\epsilon_{i}\right)}
$$

Where $\lambda_{i}$ is the loading factor; $\operatorname{var}\left(\epsilon_{i}\right)=1-\lambda_{i^{2}}$;

Formula to calculate composite reliability is

$$
p c=\frac{\left(\sum \lambda_{i}\right)^{2}}{\left(\sum \lambda_{i}\right)^{2}+\sum_{i} \operatorname{var}\left(\epsilon_{i}\right)}
$$

In the formative model using the outer model, the evaluation is based on the substance content, which can be seen on the value significance and weight of the multicollinearity. In GOF, the inner model is measured by predicting the relevant Q-square. The Q-square equation used is as follows.

$$
Q^{2}=1-\left(1-R_{1^{2}}\right)\left(1-R_{2^{2}}\right) \ldots\left(1-R_{p^{2}}\right)
$$

Where $R_{1^{2}}, R_{2^{2}}, \ldots, R_{p^{2}}$ is the R-Square of endogen variable in the model. $Q r$ is the total coefficient of determination contained in the path analysis as $R^{2}$ in regression.

The sixth step is interpreting and concluding the results. Result interpretation was based on the significance prediction of the relationship between variables. This interpretation was needed to test the significance of all relationships in the structural model. The results obtained come from the p-value, $\mathrm{t}$-value, or bootstrapping confidence interval significance tests. Bootstrapping is also needed to assess the significance of the path coefficient. 
TABLE 2 Assessment criteria for data processing using PLS method and structural model.

\begin{tabular}{ll}
\hline Criteria & Description \\
\hline Estimation of path & The estimated values for the path relationships in the structural model must be significant. \\
coefficient & Bootstrapping procedures can obtain this significant value. \\
R-Square $\left(R^{2}\right)$ for & $\begin{array}{l}\text { Results of } R^{2} 0.75,0.5, \text { and } 0.25 \text { for endogenous latent variables in the structural model indicate that } \\
\text { latent endogen variable }\end{array}$ \\
\hline
\end{tabular}

TABLE 3 Assessment criteria for data processing using PLS method and measurement model.

\begin{tabular}{|c|c|}
\hline Criteria & Description \\
\hline \multicolumn{2}{|l|}{ Reflective Measurement Evaluation } \\
\hline Loading Factor & Value loading factor should be greater than 0.7 \\
\hline Average Variance Extracted (AVE) & The value of AVE should be greater than 0.5 \\
\hline Discriminant Validity & $\begin{array}{l}\text { The square root value of AVE must be greater than the correlation value between } \\
\text { latent variables. }\end{array}$ \\
\hline Cross Loading & $\begin{array}{l}\text { Each indicator block is expected to have a higher loading for each latent variable } \\
\text { measured compared to indicators for other latent variables. }\end{array}$ \\
\hline Composite Reliability & Composite reliability should be greater than 0.6 \\
\hline Cronbach's Alpha & Cronbach's alpha value should be greater than 0.7 \\
\hline Formative Measurement Model & \\
\hline Significance of Weight Value & $\begin{array}{l}\text { The estimated values for the formative measurement model must be significant. A } \\
\text { bootstrapping procedure assessed this level of significance. }\end{array}$ \\
\hline Multicollinearity & $\begin{array}{l}\text { The manifest variable in the block should be tested for multicollinearity. The value of } \\
\text { variance inflation factor (VIF) can be used to test this. A VIF value above } 10 \\
\text { indicates that there is multicollinearity. }\end{array}$ \\
\hline
\end{tabular}

\subsection{2 | Assessment Criteria for Data Processing Using PLS Method}

There are two types of assessment in the PLS method: the structural or inner models and the measurement of outer models. A structural model can provide clues to the strength of estimation between latent or construct variables. Meanwhile, the measurement model provides clues regarding the manifest or observed variable representing the latent variable to be measured.

The assessment criteria for data processing using the PLS method using the structural model are shown in Table 2 The assessment criteria for data processing using the PLS method using the measurement model are shown in Table 3

\subsection{3 | Research Model Testing and Data Processing}

A model test was conducted in this study to determine whether learning value and trust variables added to the UTAUT2 method are valid or not. The test is conducted by comparing the results of calculations between models with a moderator of experience, gender, and age with a model that does not use the moderator. Then from this step, it can be seen that the model is suitable or not for this study.

\section{7 | Hypothesis Testing}

Hypothesis testing is carried out based on the research method with the hypothesis, then processed using PLS, which will produce a P-value (P-value). This value is used to determine whether to accept the hypothesis by comparing this value with the alpha $(\alpha)=5 \%$ to the following conditions.

- P-value $\leq$ avalue means that the hypothesis is accepted. If the hypothesis is accepted, there is a significant influence from the independent variable on the dependent variable.

- P-value $>$ avalue means that the hypothesis is rejected. If the hypothesis is rejected, there is no significant effect of the independent variable on the dependent variable. 
TABLE 4 Respondent demography data.

\begin{tabular}{|c|c|c|c|c|c|c|c|}
\hline Variable & Classification & \#Users & Percentage & Variable & Classification & \#Users & Percentage \\
\hline \multirow{12}{*}{ City } & Region 1 Medan & 6 & $6.9 \%$ & Educational & SMA/SMK & 2 & $2.3 \%$ \\
\hline & Region 2 Pekanbaru & 11 & $12.6 \%$ & Background & D1/D2/D3 & 12 & $13.8 \%$ \\
\hline & Region 3 Palembang & 2 & $2.3 \%$ & & S1/D4 & 71 & $81.6 \%$ \\
\hline & Region 4 Balikpapan & 12 & $13.8 \%$ & & $\mathrm{~S} 2 / \mathrm{S} 3$ & 2 & $2.3 \%$ \\
\hline & Region 5 Manado & 9 & $10 \%$ & User & No & 73 & $83.9 \%$ \\
\hline & Region 6 Makassar & 9 & $10 \%$ & Experience & Yes & 14 & $16.1 \%$ \\
\hline & Region 7 Denpasar & 3 & $3.4 \%$ & Duration of & Less than 1 Month & 6 & $6.9 \%$ \\
\hline & Region 8 Jakarta I & 7 & $8 \%$ & Use & $2-3$ Months & 14 & $16.1 \%$ \\
\hline & Region 9 Jakarta II & 2 & $2.3 \%$ & & 3-6 Months & 8 & $9.2 \%$ \\
\hline & Region 10 Bandung & 2 & $2.3 \%$ & & 6 Months -1 Year & 30 & $34.5 \%$ \\
\hline & Region 11 Semarang & $\overline{7}$ & $8 \%$ & & More than 1 Year & 29 & $33.3 \%$ \\
\hline & Region 12 Surabaya & 17 & $19.5 \%$ & Frequency & 1-2 times a year & 1 & $1.1 \%$ \\
\hline \multirow[t]{2}{*}{ Gender } & Male & 44 & $50.6 \%$ & of Use & $1-3$ times in 6 months & 6 & $6.9 \%$ \\
\hline & Female & 43 & $49.4 \%$ & & 1-4 times a month & 17 & $19.5 \%$ \\
\hline \multirow[t]{2}{*}{ Age } & $<30$ Years old & 39 & $45 \%$ & & 2-3 times a week & 23 & $26.4 \%$ \\
\hline & $>30$ Years old & 48 & $55 \%$ & & 5-6 times a week/every & 40 & $46 \%$ \\
\hline Marital & Single & 32 & $36.8 \%$ & & day & & \\
\hline \multirow{2}{*}{ Status } & Married & 53 & $60.9 \%$ & & & & \\
\hline & Widower/ Widow/ Others & 2 & $2.3 \%$ & & & & \\
\hline
\end{tabular}

\section{4 | RESULTS AND DISCUSSION}

This chapter will discuss the data from the results of user questionnaires, the results of the application process of the PLS-SEM method and UTAUT2 method using the SmartPLS tool in terms of data analysis and research hypothesis testing. The following are the results of user demographics in general from 87 respondents. The data can be seen in Table 4

\section{1 | Data Analysis using PLS-SEM}

Data analysis for this research uses the Partial Least Square Structural Equation Modeling (PLS-SEM) method.

\subsection{1 | Defining and Analysing Outer Model (Measurement Model)}

The determination of the outer model was carried out by combining several latent variables, exogenous and endogenous variables. An overview of the combination of these variables is presented in a diagram presented in Figure 3 It is illustrated that each variable has an indicator. Behavior Intention (BI) has three indicators (BI1, BI2, and BI3). Use Behavior (UB) has two indicators (UB1 and UB2). Effort Expectancy (EE) has four indicators (EE1, EE2, EE3, and EE4). Facilitating Conditions (FC) has three indicators (FC1, FC2, and FC3). Habit $(\mathrm{H})$ has two indicators (H1 and H2). Hedonic Motivation (HM) has three indicators (HM1, HM2, and HM3). Learning Value ( LV) has four indicators (LV1, LV2, LV3, and LV4). Performance Expectancy (PE) has four indicators (PE1, PE2, PE3, and PE4). Price Value (PV) has three indicators (PV1, PV2, and PV3 ). Social Influence (SI) has three indicators (SI1, SI2, and SI3), and Trust (T) has four indicators (T1, T2, T3, and T4).

\subsection{2 | Defining Inner Model (Structural Model)}

The inner model is defined by combining several latent variables, exogenous variables, and endogenous variables. Based on this definition, it is found that variables are interrelated with several variables, Behavior Intention (BI), Use Behavior (UB), Effort Expectancy (EE), Facilitating Conditions (FC), Habit (H), Hedonic Motivation (HM), Learning Value (LV), Performance Expectancy (PE), Price Value (PV), Social Influence (SI), and Trust (T). the relationship is illustrated in Figure 4 above. From Figure 4 , we know that variables that are part of exogenous variables are PE, EE, SI, T, PV, FC, LV, HM, and H. Meanwhile $\mathrm{BI}$ and UB are part of the endogen variable. 4.1.3 Validation and Reliability Testing Tests were carried out using data from 87 respondents. This process is performed using SmartPLS software implementing the PLS Algorithm method, with the defined criteria, Cronbach's Alpha and Composite Reliability of minimum 0.7 and an Average Variance Extracted (AVE) value of minimum 0.5. Table 5 shows the measurement results of these variables and shows the results that can be said to be reliable and valid. Therefore, the respondents can understand the questions used in this questionnaire to provide appropriate answers. After that, the questionnaire can be distributed to all respondents to obtain data used in the following research. 


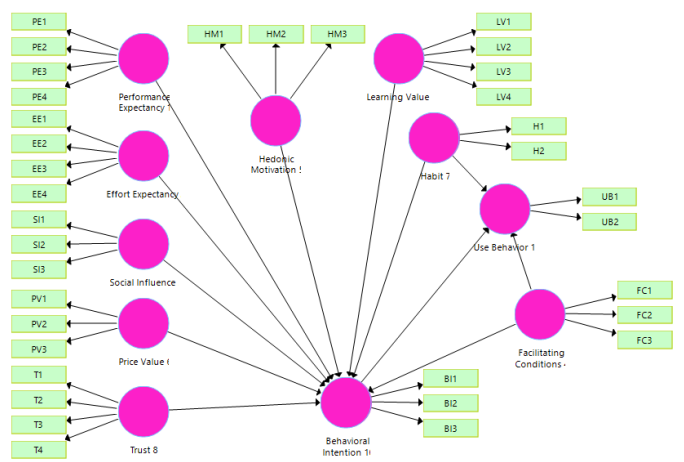

FIGURE 3 Outer model Diagram (Measurement Model).

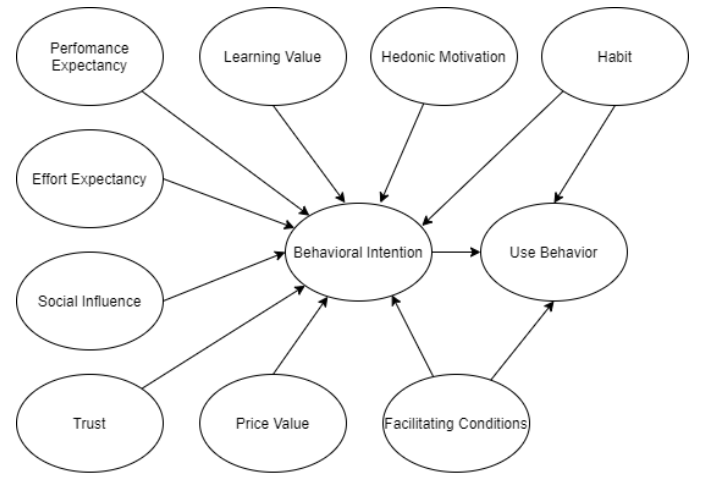

FIGURE 4 Illustration of inner model .

TABLE 5 Results of validation and reliability testing using Cronbach's Alpha, Composite Reliability, Average Variance Extracted (AVE).

\begin{tabular}{lcccl}
\hline Variable & $\alpha$ & CR & AVE & Description \\
\hline Behavioral Intention 10 (BI) & 0.745 & 0.854 & 0.662 & Data Reliable and Valid \\
Effort Expectancy 2 (EE) & 0.871 & 0.909 & 0.714 & Data Reliable and Valid \\
Facilitating Conditions 4 (FC) & 0.408 & 0.719 & 0.464 & Data Not Reliable and Valid \\
Habit 7 (H) & 0.807 & 0.910 & 0.835 & Data Reliable and Valid \\
Hedonic Motivation 5 (HM) & 0.768 & 0.848 & 0.653 & Data Reliable and Valid \\
Learning Value 9 (LV) & 0.705 & 0.807 & 0.515 & Data Reliable and Valid \\
Performance Expectancy 1 (PE) & 0.774 & 0.852 & 0.591 & Data Reliable and Valid \\
Price Value 6 (PV) & 0.765 & 0.862 & 0.681 & Data Reliable and Valid \\
Social Influence 3 (SI) & 0.723 & 0.843 & 0.642 & Data Reliable and Valid \\
Trust 8 (T) & 0.828 & 0.884 & 0.657 & Data Reliable and Valid \\
Use Behavior 11 (UB) & 0.438 & 0.706 & 0.581 & Data Reliable and Valid \\
\hline
\end{tabular}

\subsection{3 | Estimation of Path Model PLS-SEM Method}

In this path model estimation, the PLS method makes parameter estimation and other model path coefficients to maximize the type (variance) described by the dependent variable. This indicator variable is used to input raw data in estimating the value of the construct as a form of completion of the PLS-SEM method. The path description of the PLS-SEM method is illustrated in Figure 3 above. There are several variables and each indicator. Behavior Intention (BI) has three indicators (BI1, BI2, and BI3). Use Behavior (UB) has two indicators (UB1 and UB2). Effort Expectancy (EE) has four indicators ( EE1, EE2, EE3, and EE4). Facilitating Conditions (FC) has three indicators (FC1, FC2, and FC3). Habit (H) has two indicators (H1 and H2). Hedonic Motivation (HM) has three indicators (HM1, HM2, and HM3). Learning Value (LV) has four indicators (LV1, LV2, LV3, and LV4). Performance Expectancy (PE) has four indicators (PE1, PE2, PE3, and PE4). Price Value (PV) has three indicators (PV1, PV2, and PV3). Social Influence (SI) has three indicators (SI1, SI2, and SI3). Trust (T) has four indicators (T1, T2, T3, and T4).

\subsubsection{Evaluation of Measurement Model, Structural Model, and Goodness of Fit (Reflektive and Formative Model)}

This section will describe the Evaluation of the Measurement Model, Structural Model, and Goodness of Fit (Reflective and Formative Model). The first evaluation is the evaluation of outer model (Measurement Model). The measurement model is reflective, so the test indicators used are reliability, internal consistency, convergent validity, and discriminant validity. Based on these indicators, testing is carried out to determine whether or not the indicators used are appropriate and whether the indicators are feasible (reliable and valid) to be used as measurement tools.

The reliability indicator is done by looking at the outer loading (loading factor) value, which provides an overview of the correlation between each indicator/measurement variable and its construct. The indicator is the value of outer loading $>0.7$. 
TABLE 6 Evaluation of outer model: The reliability indicator.

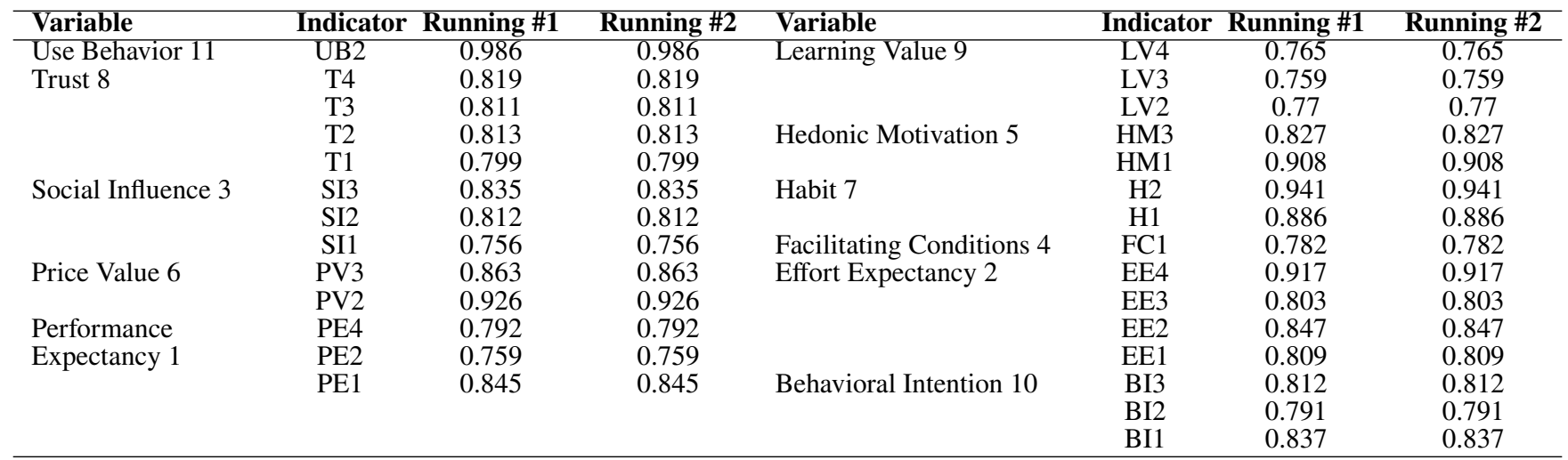

TABLE 7 Evaluation of outer model: Cronbach's Alpha and Composite Reliability.

\begin{tabular}{|c|c|c|c|c|}
\hline \multirow[t]{2}{*}{ Variable } & \multicolumn{2}{|c|}{ Cronbach's Alpha } & \multicolumn{2}{|c|}{ Composite Reliability } \\
\hline & $\alpha$ & Description & $\mathbf{C R}$ & Description \\
\hline Behavioral Intention 10 & 0.745 & Reliable Data & 0.854 & Reliable Data \\
\hline Effort Expectancy 2 & 0.871 & Reliable Data & 0.909 & Reliable Data \\
\hline Facilitating Conditions 4 & 1 & Reliable Data & 1 & Reliable Data \\
\hline Habit 7 & 0.807 & Reliable Data & 0.91 & Reliable Data \\
\hline Hedonic Motivation 5 & 0.723 & Reliable Data & 0.866 & Reliable Data \\
\hline Learning Value 9 & 1 & Reliable Data & 1 & Reliable Data \\
\hline Performance Expectancy 1 & 0.745 & Reliable Data & 0.853 & Reliable Data \\
\hline Price Value 6 & 0.817 & Reliable Data & 0.916 & Reliable Data \\
\hline Social Influence 3 & 0.723 & Reliable Data & 0.843 & Reliable Data \\
\hline Trust 8 & 0.828 & Reliable Data & 0.884 & Reliable Data \\
\hline Use Behavior 11 & 1 & Reliable Data & 1 & Reliable Data \\
\hline
\end{tabular}

Based on Table 6 seven indicator variables do not meet the specified standards: Use Behavior indicator UB1, Price Value indicator PV1, Performance Expectancy indicator PE3, Learning Value indicator LV1, Hedonic Motivation indicator HM2, Facilitating Conditions indicator FC3, and FC2. Because of this, it is necessary to eliminate the seven indicator variables. So, for the next run, there will be no indicator variables that do not meet the outer loading standard value $<0.7$. The research can be continued to the next stage, which is internal consistency reliability.

Internal consistency reliability is a measurement performed by observing the value of Cronbach's Alpha and Composite Reliability. The value that is given good reliability is a value that passed standard value $>0.7$. The result of this measurement can be seen in Table 7 After executing the data, the Learning Value construct variable obtained a Cronbach's Alpha value of less than 0.7. We deleted the indicator that has a small value. Those are LV2, then LV3. Then the data is re-executed, new data is generated below, which shows the Cronbach's Alpha value with good reliability values. When Cronbach's Alpha value on the indicator variable is reliable, we check the composite data reliability. From this check, it is identified that the value of each variable produces good reliability, as shown in Table 7

Convergent Validity is used to determine the suitability between indicator variables and theoretical concepts that describe the existence of these indicators. In this step, we observe the Average Variance Extracted (AVE) value. AVE testing can be said to have a good value if the minimum value is 0.5 , and the results are shown in Table 8 that the value of each AVE of all variables has a value in accordance with the standard so that the construct variables can be said to be all valid and usable data.

Discriminant validity describes the extent to which a construct can be said to be different from other constructs. This test compares the value of loading the intended constructs to have a higher value than the loading value of other constructs. This test uses the Heterotrait-Monotrait (HTMT) ratio, model. If the HTMT value is $>0.9$, there is a problem because of discriminant validity. The HTMT value is shown in Table 9 where no value appears to exceed 0.9 , so it can be concluded that there is no problem related to the validity value. 
TABLE 8 Evaluation of outer model: Convergent Validity.

\begin{tabular}{lll}
\hline Variable & AVE & Description \\
\hline Behavioral Intention 10 & 0.661 & Data Valid \\
Effort Expectancy 2 & 0.714 & Data Valid \\
Facilitating Conditions 4 & 1.000 & Data Valid \\
Habit 7 & 0.835 & Data Valid \\
Hedonic Motivation 5 & 0.766 & Data Valid \\
Learning Value 9 & 1.000 & Data Valid \\
Performance Expectancy 1 & 0.659 & Data Valid \\
Price Value 6 & 0.845 & Data Valid \\
Social Influence 3 & 0.642 & Data Valid \\
Trust 8 & 0.657 & Data Valid \\
Use Behavior 11 & 1.000 & Data Valid \\
\hline
\end{tabular}

TABLE 9 Value of discriminant validity.

\begin{tabular}{|c|c|c|c|c|c|c|c|c|c|c|c|}
\hline Variable & $\mathrm{BI}^{\circ}$ & EE & FC & H & HM & LV & PE & PV & SI & $\mathbf{T}$ & UB \\
\hline $\mathrm{BI}$ & & & & & & & & & & & \\
\hline $\mathrm{EE}$ & $0.350^{\circ}$ & & & & & & & & & & \\
\hline FC & $0.486^{\circ}$ & 0.247 & & & & & & & & & \\
\hline $\mathrm{H}$ & $0.632^{\prime}$ & 0.551 & 0.599 & & & & & & & & \\
\hline $\mathrm{HM}$ & $0.716^{\circ}$ & 0.577 & 0.647 & 0.758 & & & & & & & \\
\hline LV & $0.490^{\circ}$ & 0.390 & 0.205 & 0.310 & 0.397 & & & & & & \\
\hline PE & $0.537^{`}$ & 0.597 & 0.399 & 0.673 & 0.615 & 0.380 & & & & & \\
\hline PV & $0.683^{\circ}$ & 0.128 & 0.506 & 0.346 & 0.587 & 0.373 & 0.393 & & & & \\
\hline SI & $0.677^{\circ}$ & 0.608 & 0.403 & 0.664 & 0.594 & 0.434 & 0.813 & 0.426 & & & \\
\hline $\mathrm{T}$ & $0.564^{`}$ & 0.482 & 0.431 & 0.551 & 0.536 & 0.470 & 0.556 & 0.646 & 0.599 & & \\
\hline UB & $0.143^{\circ}$ & 0.066 & 0.203 & 0.411 & 0.153 & 0.009 & 0.138 & 0.046 & 0.113 & 0.119 & \\
\hline
\end{tabular}

TABLE 10 The coefficient of determinant $\left(R^{2}\right)$.

\begin{tabular}{lcl}
\hline & $R^{2}$ & Description \\
\hline Behavioral Intention 10 & 0.520 & Moderate accurateness \\
Use Behavior 11 & 0.146 & Weak accurateness \\
\hline
\end{tabular}

TABLE 11 The effect off-square (f2) variable.

\begin{tabular}{lcl}
\hline Variable Relations & $f^{2}$ & Description \\
\hline H towards BI & 0,035 & Weak effect \\
H towards UB & 0,121 & Weak effect \\
HM towards BI & 0,059 & Weak effect \\
LV towards BI & 0,039 & Weak effect \\
PV towards BI & 0,097 & Weak effect \\
SI towards BI & 0,046 & Weak effect \\
\hline
\end{tabular}

The second evaluation is the evaluation of inner model (Structural Model). The evaluation of inner model measure value of the coefficient of the determinant $\left(R^{2}\right)$, F-square (f2), cross-validated redundancy $\left(Q^{2}\right)$, dan path coefficient. Coefficient of Determinant $\left(R^{2}\right)$. The Coefficient of Determinant $\left(R^{2}\right)$ measurement shows how much influence the independent and dependent variables have. Value of $R^{2}$ ranges from zero (0) to one (1), which indicates the magnitude of the combination of the independent (free) variables which simultaneously affects the value of the dependent (dependent) variable. Variables that have a higher level indicate a better level of accuracy. The values used are 0.75 (strong), 0.50 (moderate), and 0.25 (weak). Based on the performed calculation of $R^{2}$, it shows that the endogenous variable of $\mathrm{BI}$ is 0.520 , and the value for Use Behavior (UB) variable is 0.146 . It also shows that nine other exogenous variables were included in the moderate category. The variables include Effort Expectancy (EE), Facilitating Conditions (FC), Habit (H), Hedonic Motivation (HM), Learning Value (LV), Performance Expectancy (PE), Price Value (PV) ), Social Influence (SI), and Trust (T). This fact explains that 52\% of the variance comes from the BI variable, while FC, $\mathrm{H}$, and $\mathrm{BI}$ variables have $14.6 \%$ of the variance from the UB variable. The result is presented in Table 10

Effect of F-Square (F2) Variable To measure each model path, it can be determined by calculating the value of Cohen's f2. The value of $\mathrm{f} 2$ is calculated by noting the change from $R^{2}$. When a certain construct is eliminated from the model, to calculate f2, two PLS path models are required. The first path becomes a complete model as determined from the hypothesis, then produces $R^{2}$ from the complete model. Meanwhile, both models must be the same except for the exogenous construct that has been selected to be removed from the model, resulting in $R^{2}$ from the reduced model. After that, the initial $R^{2}$ value is reduced by the reduced model $R^{2}$ value so that the $\mathrm{f} 2$ value is obtained ${ }^{[12]}$. The effect of the f-square (f2) variable in this test affects the value between variables, the value of $\mathrm{f} 2$ is 0.02 (weak), 0.15 (moderate), and 0.35 (large) can be ignored or can be said to have no effect. 
TABLE 12 Cross-validated Redundancy $\left(Q^{2}\right)$.

\begin{tabular}{lclc}
\hline Endogen Variable & SSO & SSE & $Q^{2}$ \\
\hline Behavioral Intention & 261.000 & 191.007 & 0,268 \\
Use Behavior & 87.000 & 79.124 & 0,091 \\
\hline Note: $Q^{2}=1-\frac{S S E}{S S O}$ & & &
\end{tabular}

TABLE 13 Path coefficient.

\begin{tabular}{lrrr}
\hline Relation Between Variables & $\begin{array}{r}\text { Original } \\
\text { Sample (O) }\end{array}$ & T-Statistics & P-Values \\
\hline Habit 7 $\Rightarrow$ Use Behavior 11 & 0.409 & 3.501 & 0.001 \\
Price Value 6 $\Rightarrow$ Behavioral Intention 10 & 0.290 & 2.196 & 0.029 \\
\hline Note: T-Statistics $=\frac{O}{S T D E V}$ & & &
\end{tabular}

The results off-square (f2) value can be seen in Table 11 . The table shows that several variables have a weak effect, namely $\mathrm{H}$ towards BI, H towards UB, HM towards BI, LV towards BI, LV towards BI, PV towards BI, and SI towards BI. Meanwhile, other variable relations have no effect.

Cross-validated Redundancy $\left(Q^{2}\right)$ is used to observe the effect of the relative structural model on the measurement of the endogenous latent variable. In this section, if the value of $Q^{2}$ is less than 0 , then the model has less relevant predictions. Meanwhile, if the value of $Q^{2}$ is greater than 0 , the model has a relevant predictive value and is accurate for a particular construct. The value of $Q^{2}$ has several levels, namely 0.02 (weak), 0.15 (moderate), and 0.35 (strong). This step is carried out using PLS blindfolding process. Table 12 shows that the $Q^{2}$ value in the BI variable is 0.268 , which means it has a moderate effect, while the UB variable is 0.091 , which has a weak effect.

Here, we measure the significant value and strength of the structural paths that have been hypothesized between constructs. This step is performed through PLS-SEM bootstrapping on the SmartPLS software. The path coefficient value is between minus one $(-1)$ to plus one $(+1)$. If the value is getting closer to +1 , the relationship between the two constructs is getting stronger. On the contrary, if it is closer to -1 , the relationship is getting weaker. In this study, two-tailed testing was carried out because this study did not yet know the direction of the hypothesis towards a positive $(+1)$ or negative $(-1)$ hypothesis. With the two-tailed test, the expected t-statistic value is 1.96 with alpha $(\alpha)$ equal to $5 \%$ and the p-value less than 0.05 . If these criteria are met, it can be stated that these variables have a significant effect.

As shown in Table 13 the Habit variable has a significant effect on Use Behavior (UB), and Price Value (PV) has a significant effect on Behavioral Intention (BI).

\subsection{5 | Result Interpretation}

The results interpretation is carried out based on the results of the significance prediction of the relationship between variables. These results are needed to test the significance for all relationships in the structural model. These results are from $\mathrm{p}$-value, t-value, or bootstrapping confidence interval significance tests. Bootstrapping is needed to assess the significance of the path coefficient. The results of testing all hypotheses related to exogenous and endogenous variables stated that of the 12 test hypotheses, there were three variables with significant results related to age, gender, and age. In this section, a research model is generated from several types of testing, and the overview of the model results of this study is depicted in Figure 5 and Figure 6

Figure 5 shows that there are Hedonic Motivation (HM) and Price Value (PV) variables that affect Behavior Intention (BI). Moderator variables such as age can significantly affect the Hedonic Motivation variable, and the moderator variable for experience can also be said to have a significant effect on the Hedonic Motivation and Price Value variables. Whereas in Figure 6 it is known that habit affects Use Behavior (UB), there are also moderator variables such as experience, which significantly affect the Habit $(\mathrm{H})$ variable. The final result of hypothesis testing is presented in the can be seen in Table 14 


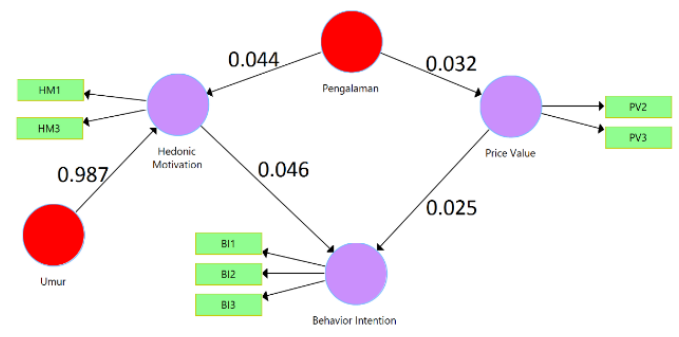

FIGURE 5 Research Result Model using Behavior Intention.

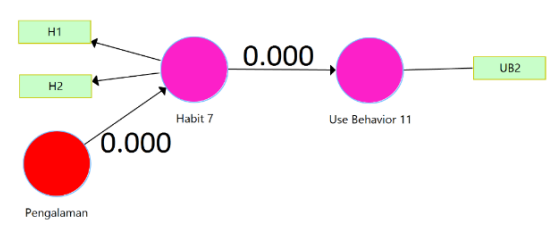

FIGURE 6 Research Result Model using Use Behavior.

TABLE 14 The final result of hypothesis testing.

\begin{tabular}{lclc}
\hline Variables & Hypothesis & Description & Result \\
\hline Hedonic Motivation (HM) & H5 & $\begin{array}{l}\text { Regarding variable age, gender, and } \\
\text { experience, does HM has a positive effect } \\
\text { on BI. }\end{array}$ & Significant \\
Price Value (PV) & H6 & $\begin{array}{l}\text { Regarding variable age and gender, does PV } \\
\text { has a positive effect on BI. } \\
\text { Regarding variable age, gender, and } \\
\text { experience, does H has a positive effect on } \\
\text { UB. }\end{array}$ & Significant \\
Habit (H) & H9 Significant \\
& &
\end{tabular}

\section{2 | Final Results and Recommendation}

Based on the conducted research that has been done, its dhows that several variables are known to influence this research significantly. From the results of this study, we summarize several recommendations that can be used as recommendations regarding the acceptance of this ERP system. Three main variables are significant, Hedonic Motivation, Price Value, and Habit.

\subsection{1 | Effect of Hedonic Motivation (HM) on Behavioral Intention (BI)}

Based on the test results, the effect of path coefficient between HM and BI construct variables, the results of the t-statistic value of 2,000 and p-value of 0.046 with the criteria used in this study where alpha $(\alpha)$ value equals $5 \%$, the path coefficient can be declared significant if the t-statistic value is geq 1.96 and the p-value leq 0.05 . So, it means that HM has a significant effect on $\mathrm{BI}$ in the acceptance of the use of ERP technology.

In this company, only two reliable measurement indicator variables associated with Hedonic Motivation (HM) are left, pleasant use (HM1), and willingness to use (HM3). In this case, users get a kind of happiness because they get new experiences when using new technology in their environment, and it can be a desire that more users pay attention to and use it. In the Hedonic Motivation variable, there is also an influence from the moderate variables, age, and experience, where most have never known or used the system before, it means that users not only paying attention to their performance but also to the feelings that users get when using this new technology. Hence, that desire appears in hedonic motivation, which is the second strongest factor that can affect user behavior towards applying the technology in previous research Venkatesh et al. [5].

To maintain the users' use of the system, we recommend the system developer maintain system reliability, such as periodically checking the database. The longer it is used, the system will continue to add data from various transactions. The frequent occurrence of system downs, errors, and failures may occur during periodic evaluations. This periodic evaluation is conducted to determine the needs of users in the field from a small module. This evaluation helps identify which parts should be maintained or updated for the user's convenience to use the system. This will help users feel more comfortable using the system. Then regarding the user interface could be simplified according to user needs or from the many columns of data so that it is clearly and consistently informed as to which parts the user should fill in. This can help reduce data filling errors. Another thing that can help users is also related to technical guidelines (user manual) to make it more detailed and interesting with flow and information by using language that users can understand because sometimes describing system language into daily language is not so easy. 


\subsection{2 | Effect of Price Value (PV) on Behavioral Intention (BI)}

Based on the test results of the effect of the path coefficient between the PV and BI construct variables, where the t-statistic value is 2.254 and p-value 0.025 , this value states that PV has a significant effect on BI in the acceptance of ERP technology use.

Variable Price Value (PV) describes the comparison between costs and benefits and the value obtained from the use of this technology. The moderate variable, the experience variable, is quite significant in influencing the PV variable. There are two reliable measurement indicator variables in the PV variable, i.e., benefits compared to costs (PV2) and value compared to costs (PV3). It means that users feel the benefits and values are greater than the costs incurred so that users are willing to apply new technology to their environment. This difference is probably due to the environmental effect and the type of technology so that users accept using the technology and become more productive in improving their performance.

In terms of Price Value, suggestions that can be applied are related to negotiations, during the initial process of collaborating, designing system implementation, until the system runs within a company, and over time the system is used, so that the system provider continues to maintain the reliability of the system. It can give users the best benefits that they can continue to use, making it easier to carry out their routine work with the system. During the initial negotiation process with an affordable system price, the provider can provide attractive offers for both the provider and the company. In this case, more solid coordination between teams can also be done so that both system users and system providers can find out the problems that occurred to be immediately handled properly. This strategy would make users feel that the user gets quality the cost incurred. These things can build user trust in the ERP system service providers, and indirectly there could be branding media between users and their environments who might want to know about the system.

\subsection{3 | Habit on Use Behavior (UB)}

Based on the test results, the effect of path coefficient between the PV and BI construct variables resulted in a t-statistic value of 3.557 and a p-value of 0.000 , which means that PV has a significant effect on BI in accepting the use of ERP technology. Another variable with a significant effect is Habit $(\mathrm{H})$, and the moderate variable that has a significant effect is user experience. This variable affects the user behavior (UB) but not the behavior intention (BI) variable. Habit can describe how the user tends to do something instinctively because he already knows beforehand. Habit can be a significant influence in using a system. It was indicated by how fast time changes, various new things, and other things that continue to innovate ( Venkatesh et al., 2012). There are two reliable measurement indicator variables in the $\mathrm{H}$ variable, namely habit (H1) and necessity (H2). These factors are like a daily routine and have become a habit that is indeed quite difficult to leave. The number of transactions and records that must be done will make user habits in accepting this technology positively. Suggestions that can be applied to users are that they should record more transactions with various types of processes and documents to be more familiar with the system so that users can more smoothly carry out various recording transactions. For system providers and users in the company, it is better to conduct an evaluation every few months/years to find out more about what needs to be improved so that later they know whether the system is in accordance with the company's rules or not. Then for the matters relating to human resources, the company should conduct regular online training to improve the ability of users in the company in using the systems.

\subsubsection{Effect of Behavioral Intention (BI) on Use Behavior (UB)}

Based on the test results for the effect of the path coefficient between BI and UB construct variables, the t-statistic value is 0.673 and p-value 0.501, which states that BI has no significant effect on UB in accepting the use of ERP technology. There are three indicator variables in BI, indicators of intention (BI1), habits (BI2), and interest in use (BI3). Meanwhile, the UB variable is the indicator of intensity (UB1) and experience (UB2). Then related to reliable data on BI variables, namely BI1, BI2, and BI3, meet the standard criteria in the Reliability Indicator process. While in the UB variable, there only the UB2 variable is left. In the moderator variables, gender, age, and experience here also have no significant effect on the influence of the Behavioral Intentions variable on Use Behavior. From these results, it can be concluded that the user's intention, habit, and interest in using the system don't significantly affect the experience. This is likely because some users still do not feel comfortable using the system which is still being developed. 


\subsection{5 । Effect of Effort Expectancy (EE) on Behavioral Intention (BI)}

Based on the test results for the effect of the path coefficient between the EE and BI construct variables resulted in a t-statistic value of 0.465 and a p-value of 0.642 , EE has no significant effect on BI in accepting the use of ERP technology. There are three indicator variables in EE, indicators that are easy to understand (EE1), easy to use (EE2), new features that are easy to learn (EE3), and easy to become proficient (EE4). All indicator values of EE variables meet the standard criteria of the Reliability Indicator process, which means that data is reliable. In the moderator variables, gender, age, and experience also do not significantly affect the EE variable's effect on Behavioral Intentions.

The obtained result is most likely because some users still do not understand the system's features. Assistance is needed from local support who understands the system by interpreting it into a daily language to make it easier for users to understand.

\subsubsection{Effect of Facilitating Conditions (FC) on Behavioral Intention (BI)}

Testing the effect of the path coefficient between the FC and BI construct variables obtained a t-statistic value of 0.134 and a p-value of 0.893, which means that FC has no significant effect on BI in the acceptance of the use of ERP technology. There are three indicator variables in FC knowledge ownership indicator (FC1), compatibility (FC2), and assistance (FC3). Meanwhile, BI variables are indicators of intention (BI1), habits (BI2), and interest in use (BI3). At the same time, the reliable data on the remaining FC variable is FC1, where the value meets the standard criteria in the Reliability Indicator process. All indicator variables of the BI variable also passed the standard. In the moderator variables, gender, age, and experience also do not significantly affect the FC variable's effect on Behavioral Intentions.

The results obtained are most likely because the system is sometimes still having problems with unstable networks. So, when a user makes a transaction, the documents used as a reference are still using the old business process calculations. Sending data from the old system to the new system is still not perfect because the contents of the data sent when received are still not synchronized. Therefore, etc. Sometimes, the interest in using the system may still be lacking if it is not in an urgent condition.

\subsection{7 | Effect of Facilitating Conditions (FC) on Use Behavior (UB)}

The results of testing the effect of the path coefficient between the construct variables of FC and UB get a t-statistic value of 0.205 and p-value of 0.837 , which means that the FC variable does not have a significant effect on UB in the acceptance of the use of ERP technology. There are three indicator variables in FC, knowledge ownership indicator (FC1), compatibility (FC2), and assistance (FC3). In the UB variable, there is the indicator of intensity (UB1) and experience (UB2). Meanwhile, the remaining reliable data on the FC variable is FC1, where its value meets the standard criteria in the Reliability Indicator process. While in the UB variable, only the UB2 indicator has an indicator value that meets the standard. In the moderator variables, gender, age, and experience also have no significant effect on the influence of the FC variable on Use Behavior. This result is most likely because the users don't have much experience with the technology, making it difficult to use the system.

\subsubsection{Effect on Habit (H) on Behavioral Intention (BI)}

The test results for the effect of the path coefficient between the construct variables $\mathrm{H}$ and BI have a t-statistic value of 1.190 and a p-value of 0.235 , which means that $\mathrm{H}$ does not significantly affect $\mathrm{BI}$ in the acceptance of the use of ERP technology. However, the Habit variable has a significant effect on UB. There are three indicator variables in H: habit (H1) and necessity (H2). Meanwhile, the BI variables are indicators of intention (BI1), habits (BI2), and interest in use (BI3). All data of variables $\mathrm{H}$ and BI all meet the standards in the Reliability Indicator process. The results obtained are probably because there are several new users due to employee mutations, etc. so that some of these new users are not familiar with using this technology.

\subsection{9 $\quad$ Effect of Learning Value (LV) on Behavioral Intention (BI)}

Testing the effect of the path coefficient between the LV and BI construct variables obtained a t-statistic value of 1.661 and a p-value of 0.097, which states that LV has no significant effect on BI in the acceptance of the use of ERP technology. There are three indicator variables in LV, indicators related to benefits compared to effort (LV1), ease of transactions (LV2), learning 
opportunities to learn something new quickly (LV3), and opportunities to increase knowledge (LV4). Only the LV4 variable has reliable data 1 variable, where the value meets the standard criteria in the Internal Consistency Reliability process. In the moderator variables, gender, age, and experience also have no significant effect on the effect of the LV variable on Behavioral Intentions.

Based on the result, we assume that some users still do not understand the details of the system, so it is not possible to share knowledge with other people around them in an easier way. For this reason, for the technology to be more useful, the local support should share their knowledge with users. Users should frequently exchange ideas with local support. Thus, the users can understand the system better and, in the future, can share knowledge with their surroundings.

\subsubsection{0 | Effect of Performance Expectancy (PE) on Behavioral Intention (BI)}

Testing the effect of the path coefficient between the PE and BI construct variables obtained a t-statistic value of 0.262 and a p-value of 0.794, which means that PE has no significant effect on BI in the acceptance of the use of ERP technology. There are three indicator variables in PE, indicators of utility (PE1), increased opportunities (PE2), structured completion (PE3), and increased productivity (PE4). They are then related to reliable data on the remaining PE variables, PE1, PE2, and PE4, where its values meet the standard criteria in the Reliability Indicator process. In the moderator variables, gender, age, and experience also did not significantly affect the effect of the PE variable on Behavioral Intentions. This might happen due to relatively new technology for some users, and its interface is also much different from the previous system. Thus, the users should learn the system again so that when inputting data, users can get used to the system's language, which is more structured and detailed.

\subsubsection{1 | Effect of Social Influence (SI) on Behavioral Intention (BI)}

Testing the effect of path coefficient between the SI and BI construct variables obtained a t-statistic value of 1.517 and a p-value of 0.130, which means that SI has no significant effect on BI in the acceptance of the use of ERP technology. There are three indicator variables on SI, indicators of use around (SI1), perceptions of people around them (SI2), and influence of people around them (SI3). Then, regarding the SI variable's reliable data, all the indicator values meet the standard criteria in the Reliability Indicator process. In the moderator variables, gender, age, and experience also have no significant effect on the influence of the SI variable on Behavioral Intentions. This is probably because the users' interests and habits on the previous system were more concise and easier. In contrast, in the new system, the influence of the surrounding environment is less believed to affect fellow users because some users may not understand in detail the structure of data recording, and not many users have previous experience and knowledge of this system.

\subsubsection{2 | Effect of Trust (T) on Behavioral Intention (BI)}

Testing the effect of the path coefficient between the construct variables $\mathrm{T}$ and BI get a t-statistic value of 0.203 and a pvalue of 0.839 , which means that $\mathrm{T}$ has no significant effect on $\mathrm{BI}$ in the acceptance of the use of ERP technology. There are three indicator variables on T, the user interest indicator (T1), trustworthiness (T2), performance (T3), and security (T4). Regarding the reliable data on the $\mathrm{T}$ variable, all indicator values meet the standard criteria in the Reliability Indicator process. In the moderator variables, gender, age, and experience also have no significant effect on the influence of the Trust variable on Behavioral Intentions. This is probably due to systems that often have unstable networks; sometimes, data are incompatible when sent from different systems. The user's trust in the system is still not very influential in current system technology.

\section{5 | RECOMMENDATIONS}

\section{1 | Recommendations for Technology/Management Provider}

Recommendations for technology provider consists of three variables that have been tested in this research. The following variables, Hedonic Motivation, Habit, and Price Value, will be explained in the next sections. 


\subsection{1 | Hedonic Motivation}

Based on the analysis results related to Hedonic Motivation, an unstable network is one of the problems. Routine maintenance should be conducted so that the system network instability does not occur when the user uses the system. In the future, since the database required for each company is different, it is better if the company should increase the storage size, so there will be space for additional data that is more than estimated per day or monthly or yearly. For the user interface, it will be better to simplify the interface according to user needs or based on the amount of data columns to be more clearly and consistently informed as to which parts should be filled in by the user. It also can help to reduce data filling errors. Another thing that can help users is related to technical guidelines (user manual). It is better to make it more detailed and interesting with flow and information in a language that users can understand. For providers to have more users of this system, it is preferable that in the marketing area, an overview of the system's advantages is provided so that users can understand the system better and share their knowledge with other users. To update the system, distributing a questionnaire should be carried out to determine user needs. During development, there will be a more clear two-way communication regarding user expectations with the system.

\subsection{2 । Habit}

Technology providers and companies should conduct an evaluation every few months/years to find out more about what things need improvement to find out whether this system is in accordance with the company's rules. For the matters relating to HR, companies should conduct regular online training to improve the ability of users in the company regarding using the systems.

\subsection{3 | Price Value}

The negotiation occurs during the initial process of collaborating, designing system implementation, and until the system runs within a company. Negotiation also could occur over time the system is used. Thus, the system provider continues to maintain the reliability of the system. Furthermore, it can provide the best benefits that can continue to be used by users and make it easier for users to implement routine work on the system. During the initial negotiation process with an affordable system price, the provider can provide attractive offers for both the provider and the company. This situation can also form more solid coordination between teams so that both system users and system providers can also find out the constraints so that they can be immediately handled properly, and users can feel that there is a system quality in accordance with the costs incurred. These can build the trust of the company's users in the ERP system service providers so that indirectly there can be branding media between users to others who might want to know about the system.

\section{2 | Recommendations from System Users}

Based on the conducted research, system users recommend multiplying user accounts. Therefore, some records can be inputted faster without taking turns using the system, synchronizing data on the system, and adjusting the language used on the system with the company environment. Thus, it is easier for users to understand, perform automatic data backup to prevent data loss when the system suddenly goes offline or an error occurs when the user is inputting data. The efficiency of work processes should be more efficient and easier for users to make transactions, provide a more detailed explanation on technical guidelines (user manual) related to system processes so that users can more easily learn about the system.

\section{3 | Future Research}

Future research can be conducted by adding other construct variables that are likely to affect this system or by adding the number of samples with more users. Research using other acceptance methods can also be implemented to compare with this study's natural methods or compare data analysis from other companies with company data in this study.

\section{6 | CONCLUSION}

In this research, factors that have a significant effect on the acceptance of SAP ERP technology are Hedonic Motivation (HM), Habit $(\mathrm{H})$, and Price Value (PV). At the same time, other variables which do not seem to have a significant effect are Trust (T), Learning Value (LV), Performance Expectancy (PE), Effort Expectancy (EE), Social Influence (SI), Facilitating Conditions 
(FC). In Hedonic Motivation, there is a kind of happiness that users obtain because they get new experiences when using new technology for their environment. This can be a desire for more users to pay attention to and use it. Also, for habit, because it is a routine that is carried out daily and has become a habit that is quite difficult to leave, the number of transactions and records that must be done will help the user accept this technology and become a habit to do. Meanwhile, users feel the benefits are greater than the costs incurred for variable PV, so users are willing to use new technology for their environment. So from the three variables, we can conclude that the LS associated with the EE and SI variables does not significantly influence the acceptance of the system.

Recommendations for strategies that can be implemented to increase the acceptance rate of the ERP system for the users is the system provider should now focus on matters related to Hedonic Motivation (HM), Habit (H), and Price Value (PV). For example, more transactions are made to familiarize users using the system, which will be more reliable, and users will continue using the new system. Also, the coordination between teams will be more solid and will obtain the benefits of applying the system, which makes users want to learn more about new things related to the system. Paying more attention to the smallest needs of users can also be very helpful in using the system. An evaluation can be held every few months/years to determine whether the user needs it or not, so improvement can be applied in the future. Users may have another factor that can influence their acceptance of the system. The system provider will become a trusted and best partner for his clients in the future because the purpose of this system is also quite important for service providers for users such as SAP ERP system providers.

\section{ACKNOWLEDGMENT}

The authors would like to thank Institut Teknologi Sepuluh Nopember and the Ministry of Research, Technology and Higher Education of Indonesia for supporting the research.

\section{CREDIT}

Baiq Findiarin Billyan: Conceptualization, Methodology, Writing-original draft preparation and supervision; Formal analysis and investigation; Mohammad Isa Irawan: Supervison, Writing-review and editing.

\section{References}

1. Syafiera T, Lubis M, Witjaksono RW, Anggana HD. The Means of Engagement (MOE) Model of the Agreement towards the Enterprise Resource Planning (ERP) Implementation. In: Fourth International Conference on Informatics and Computing (ICIC) Semarang: IEEE; 2019. p. 1-6. https://ieeexplore.ieee.org/document/8985900/,

2. Monk E, Wagner B. Mis title. In: 19th International Conference on Sciences and Techniques of Automatic Control and Computer Engineering (STA) Boston: IEEE; 2019. p. 1-11. https://ieeexplore.iee.org/document/8717284/

3. Glowalla P. A Process Management Perspective on Future ERP System Development in the Financial Service Sector. AIS Transactions on Enterprise Systems 2012;3(1):18-27.

4. Venkatesh V, Morris MG, Davis GB, Davis FD. User acceptance of information technology: Toward a unified view. MIS Quarterly: Management Information Systems 2003;27(3):425-478.

5. Venkatesh V, Thong JYL, Xu X. Consumer acceptance and use of information technology: Extending the unified theory of acceptance and use of technology. MIS Quarterly 2012;36(1):157-178.

6. Tarhini A, El-Masri M, Ali M, Serrano A. Extending the UTAUT model to understand the customers' acceptance and use of internet banking in Lebanon. Information Technology \& People 2016 nov;29(4):830-849. https://www.emerald.com/ insight/content/doi/10.1108/ITP-02-2014-0034/full/html

7. Ketchen DJ. A Primer on Partial Least Squares Structural Equation Modeling. Long Range Planning 2013 feb;46(1-2):184185. https://linkinghub.elsevier.com/retrieve/pii/S0024630113000034 
8. El-Masri M, Tarhini A. Factors affecting the adoption of e-learning systems in Qatar and USA: Extending the Unified Theory of Acceptance and Use of Technology 2 (UTAUT2). Educational Technology Research and Development 2017 jun;65(3):743-763. http://link.springer.com/10.1007/s11423-016-9508-8

9. Ain NU, Kaur K, Waheed M. The influence of learning value on learning management system use: An extension of UTAUT2. Information Development 2015;32(5):1306-1321.

10. Gefen D, Karahanna E, Straub DW. Inexperience and experience with online stores: The importance of TAM and trust. IEEE Transactions on Engineering Management 2003;50(3):307-321.

11. Chandra S, Srivastava SC, Theng YL. Evaluating the Role of Trust in Consumer Adoption of Mobile Payment Systems: An Empirical Analysis. Communications of the Association for Information Systems 2010;27(1):561-588. https://aisel. aisnet.org/cais/vol27/iss 1/29.

12. Harja YD, Mohammad, Irawan I, Ambarwati R. Measure The Significance of Learning Value and Trust Factors for Online Learning Technology Acceptance in Indonesia. IPTEK The Journal for Technology and Science 2019 November;31(2):188200. https://iptek.its.ac.id/index.php/jts/article/view/5583

How to cite this article: Billyani B.F., Irawan M.I. (2021), Analysis of Technology Acceptance of Enterprise Resource Planning (ERP) System In The Regional Office Of PT. XYZ Throughout Indonesia, IPTEK The Journal of Technology and Science, 32(2):81-102. 